\title{
حجية الشيع المقضي به وحق المحكوم عليه في طلب إعادة النظر
}

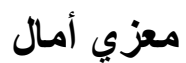 \\ كلية الحقوق \\ جامعة قسنطينة الإخوة منتوري \\ قسنطينة
}

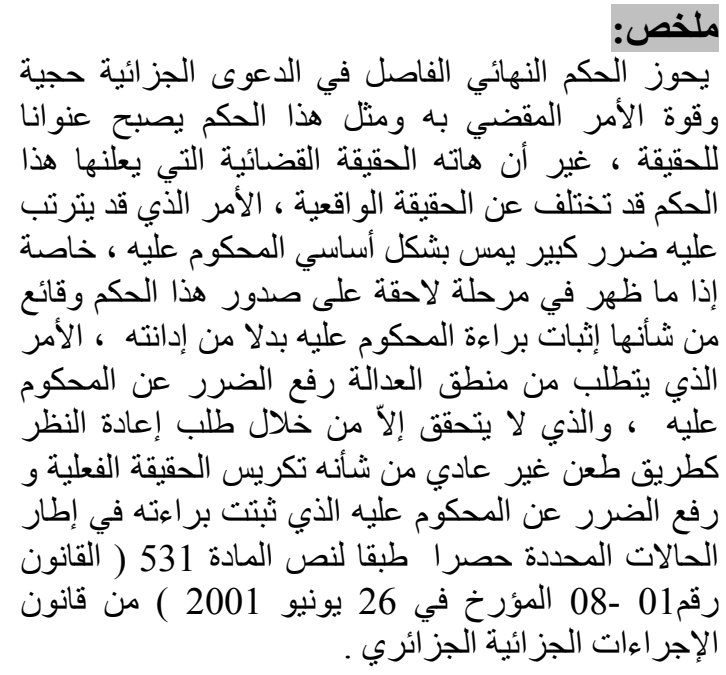

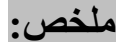

يحوز الحكم النهائي الفاصل في الدعوى الجزائية حجية

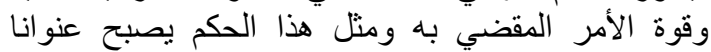

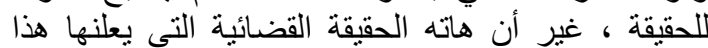

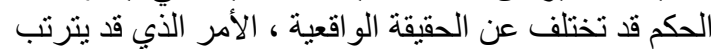

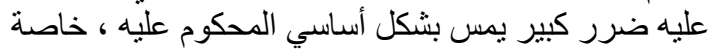

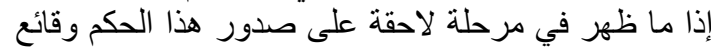

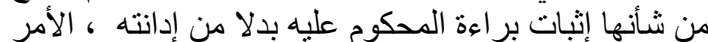

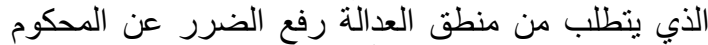

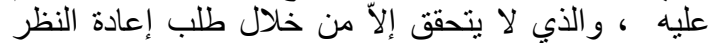

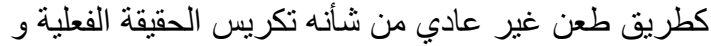

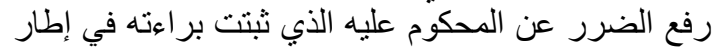

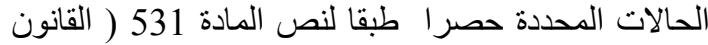

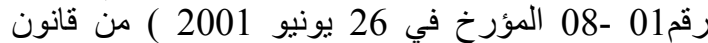
الإجر اءات الجز ائية الجزائري ل

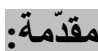

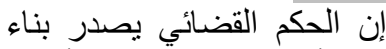

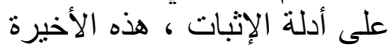

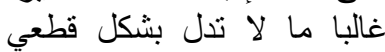

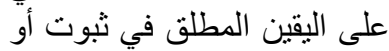

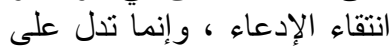

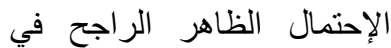

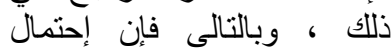

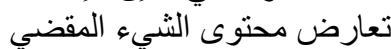
به مع واقع الأمر يبقى وارديء المقدي،

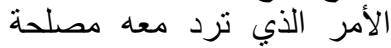

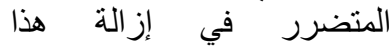
التعارض . المنرز

و إذا كانت حجية الأمر المقضي به قد تقررت لتحول دون بحث

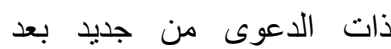
الفصل في موضوعها حفاظا

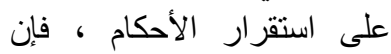
طلب إعادة النظر قد تقرر

\begin{abstract}
:
In a panel case, the final verdict has in hand strong provided evidence according to which it has been sentenced. Such a verdict represents the facts of the case in hand. However, it does not reflect the actual facts. This results in causing serious damage to the sentenced person who could later prove to be innocent after having pronounced the final verdict condemning them. In such circumstances, justice could only be done by repairing the damage caused to the sentenced person. This involves requesting a certiorari as a recourse procedure that is supposed to reveal the actual facts of the case, and repair the damage caused to the sentenced person; who proves to be innocent according to what has been set up in the rules laid down in the Algerian code of criminal procedures (Article 531 Rule $N^{\circ}$ 01- 08 of June $26^{\text {th }} 2001$ ) .
\end{abstract}




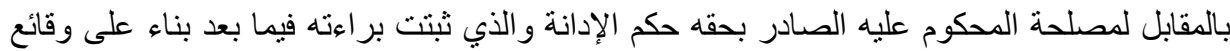

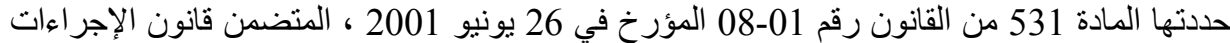

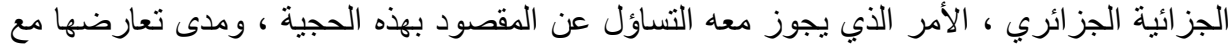

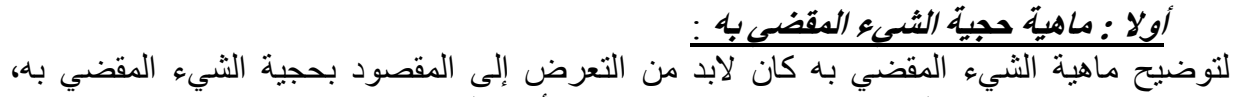

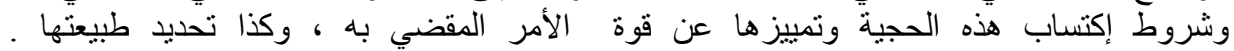

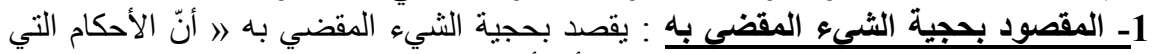

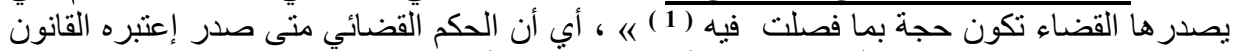

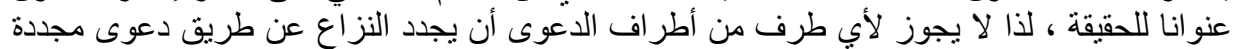

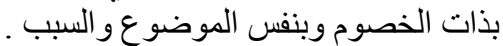
و هناك من يعرّف الحجية في هذا الصدد بأنها : 》 الصفة غير القابلة للمناز عة و الثابتة بواسطة القانون

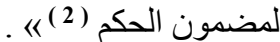

وبالتالي فالحجية مرتبطة بالحكم ، حيث يعرّف الحكم لغة بأنه : 》 القضاء ، يقال حكم له وحكم عليه ،

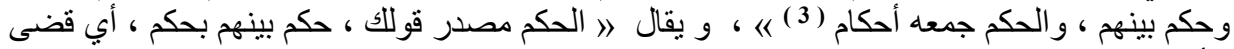

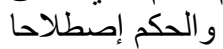

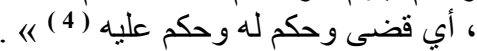

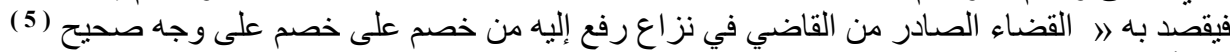

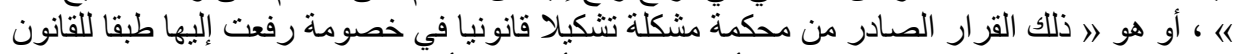

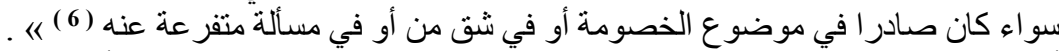

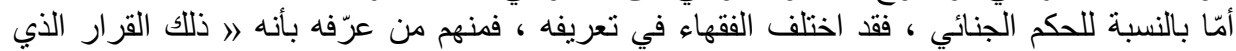

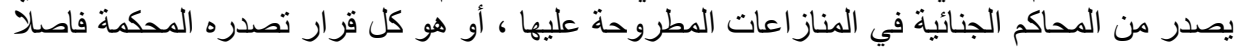

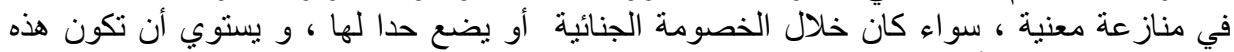

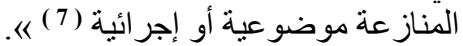

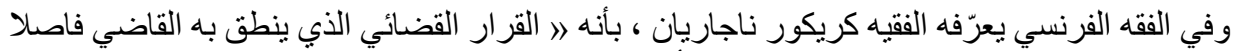

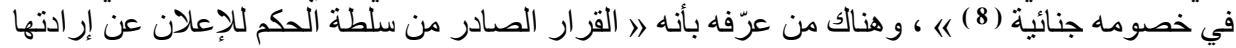
في موضوع الدعوى الجنائية بالبراءة أو الإدانة ، أو سابقا على الفئ الفصل في الموضو عالئ كالحكم بالإفراج

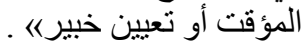

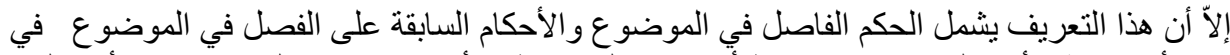

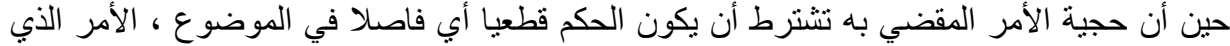

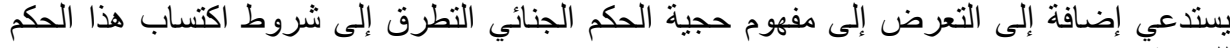
للحجية.

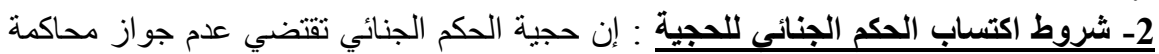

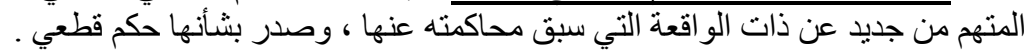

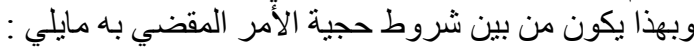

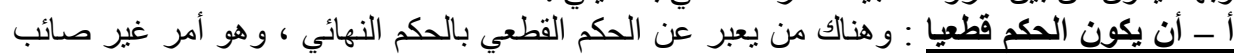

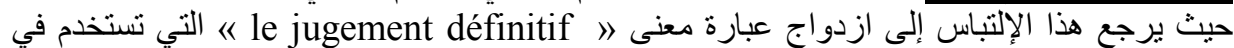

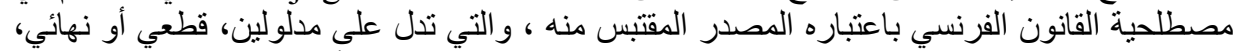

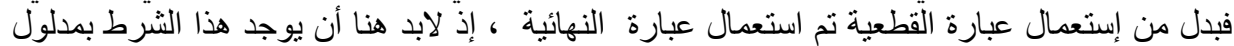

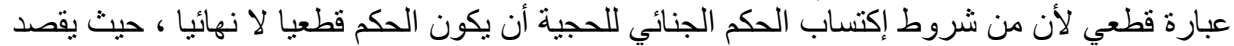

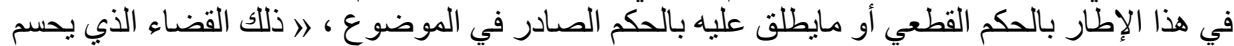

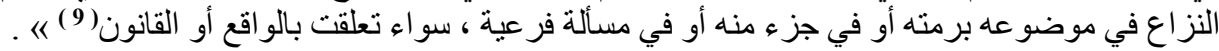


وبهذا يشترط في الحكم الجنائي في هذا الصدد ، أن يكون فاصلا في الموضوع سواء كان الإن الحكم

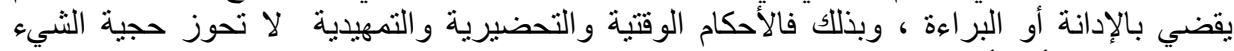

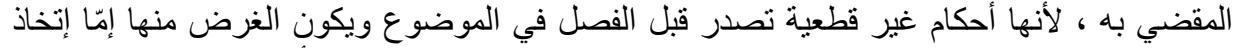

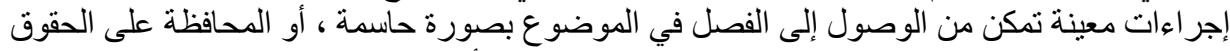

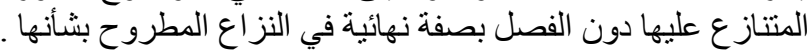

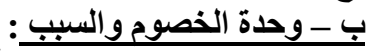

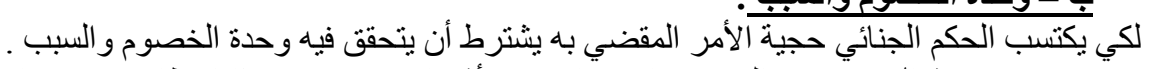

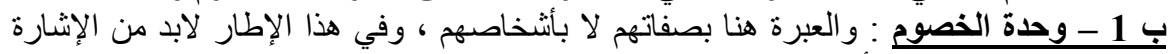

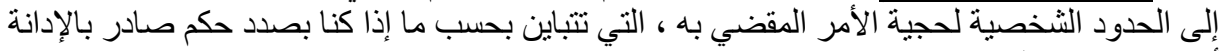

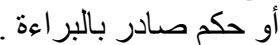

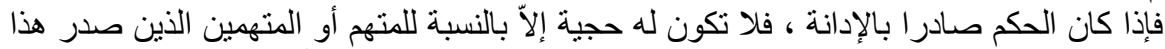

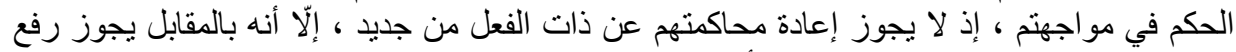

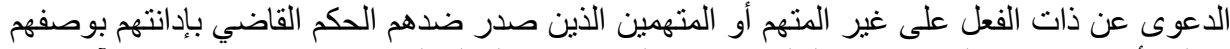

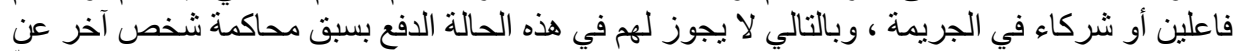

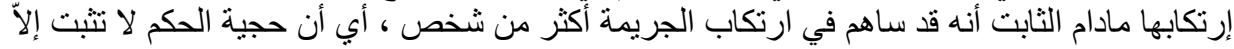

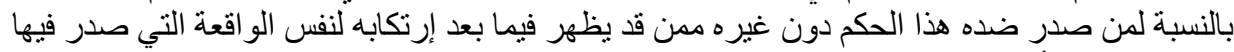

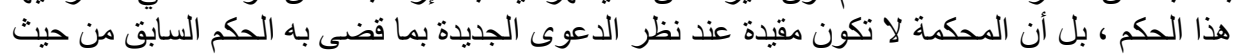

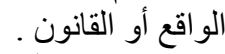

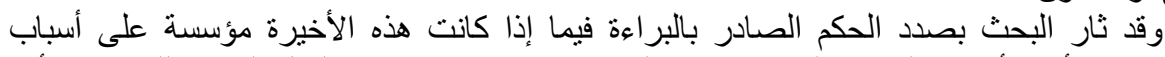

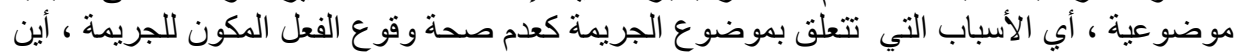

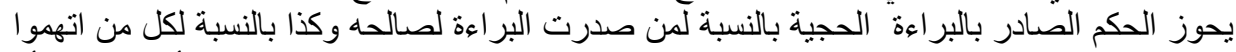

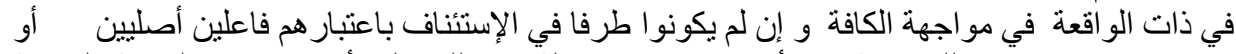

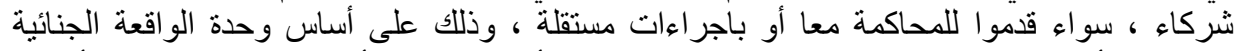

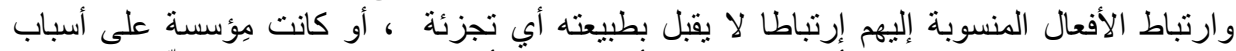

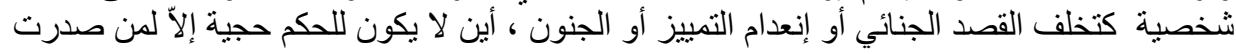

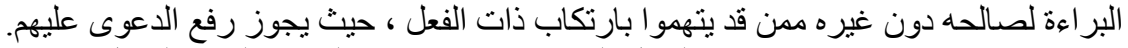

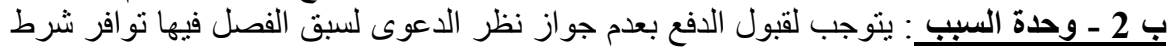

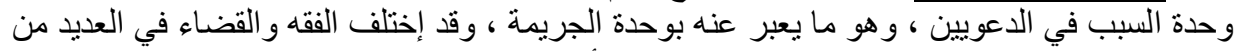

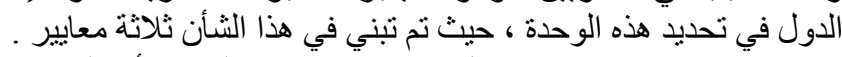

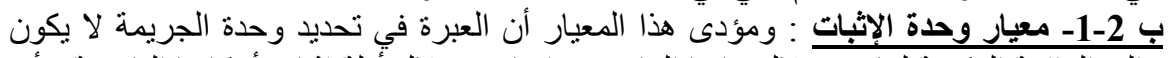

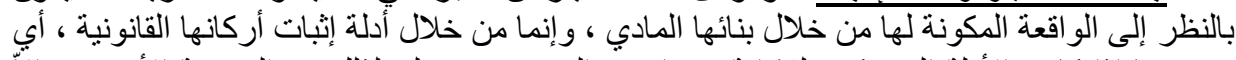

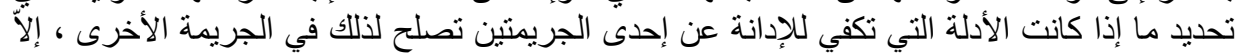

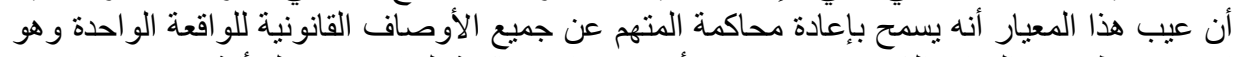

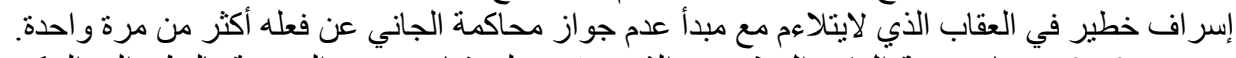

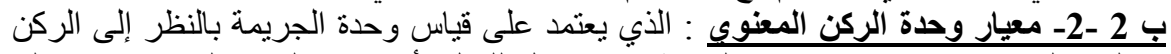

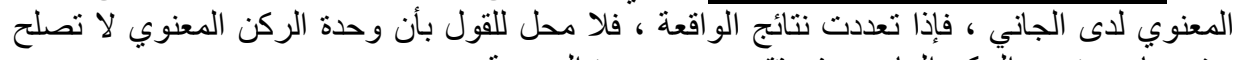

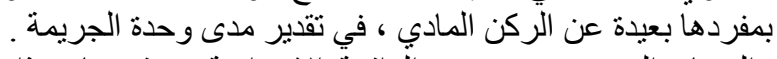

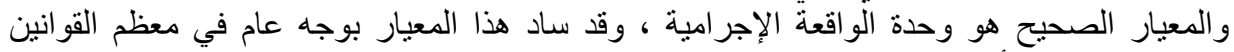

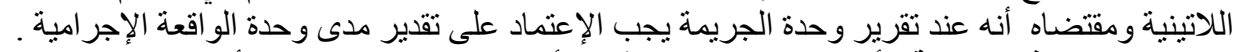

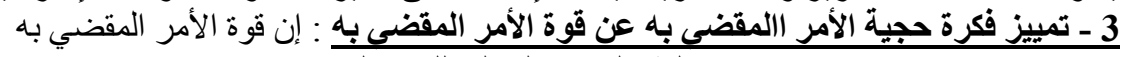
》 la force de la chose jugée » إجر ائية معينة تحول دون قابليته للطعن بأي طريق من طرق ألطعن العادية ، سواء بصدوره بعير فابل فيل 


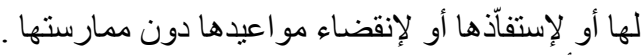

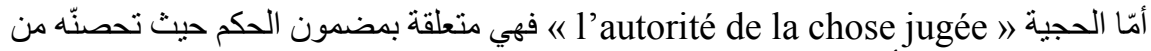

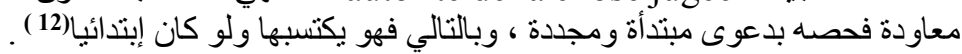

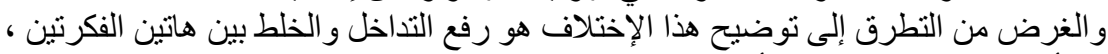

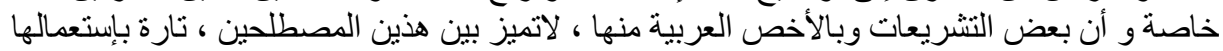

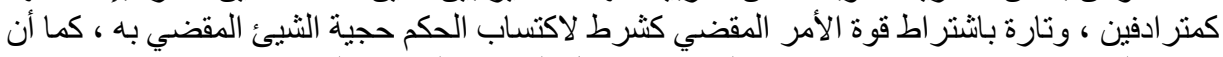

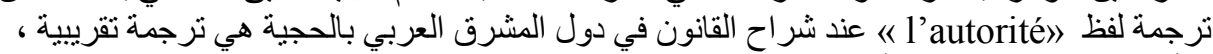

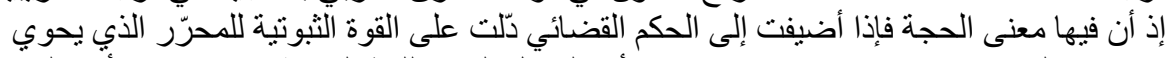

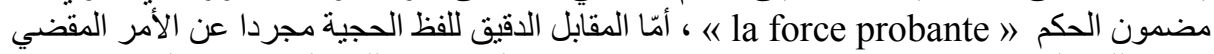

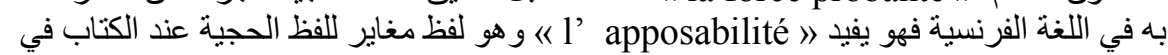

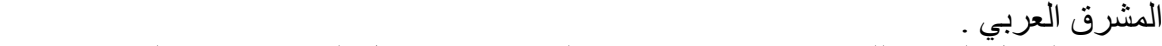

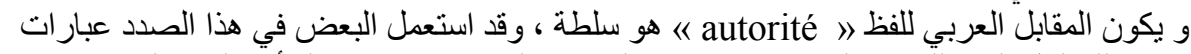

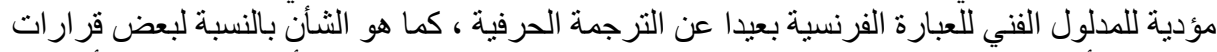

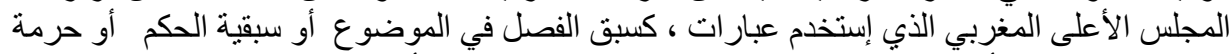

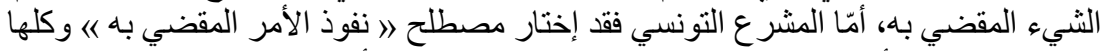

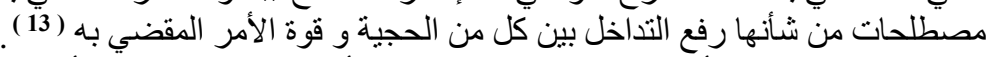

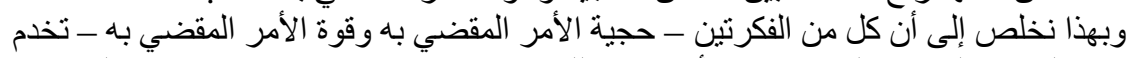

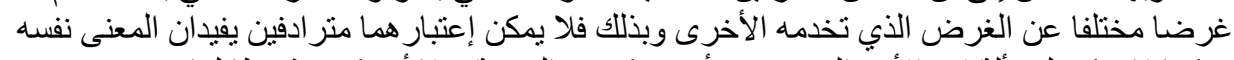

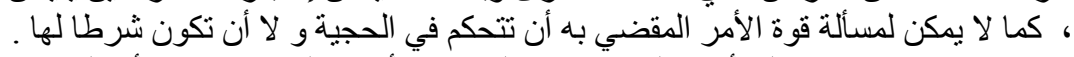

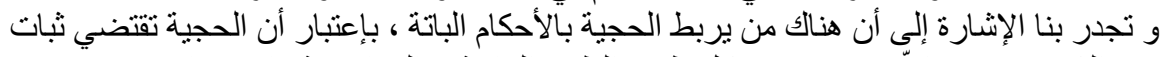

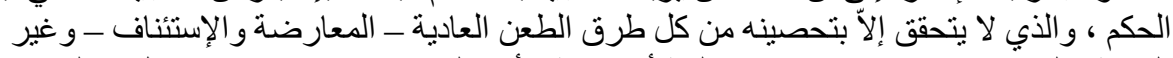

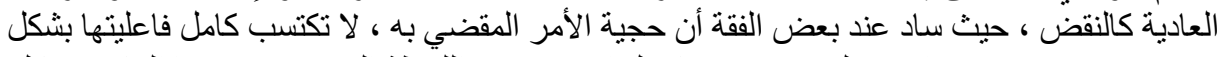

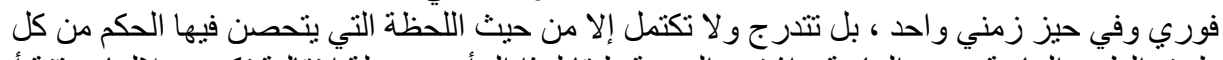
طرق الطعن العادية وغير العادية ، إذ تمر الحجية طبقا لهذا الر أي بمرحلة إنتقالية تكون خلالها مؤقتتة أو فئ معلقة أو قلقة (14).

غير أن الربط بين حجية الحكم والحكم البات أمر غير صائب ، كون البتية يتحدد مجال إعمالها

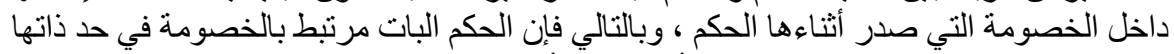

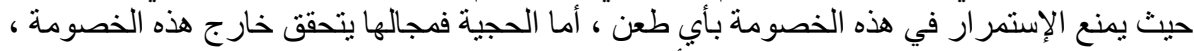

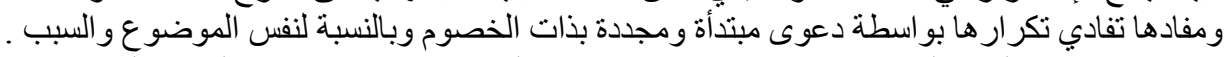

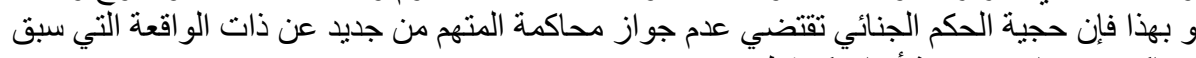

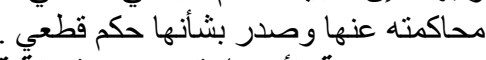

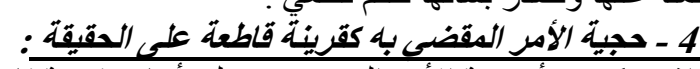

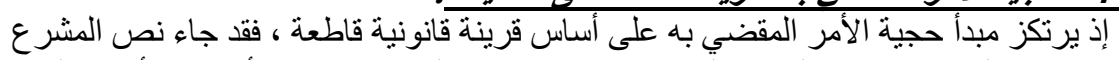

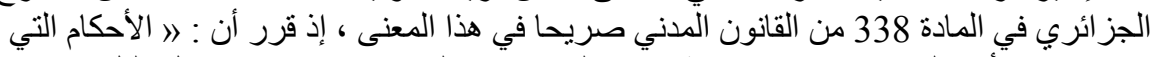

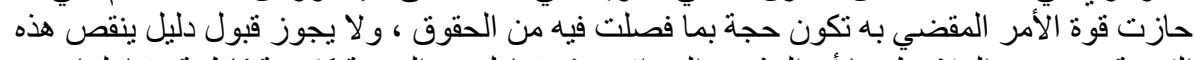

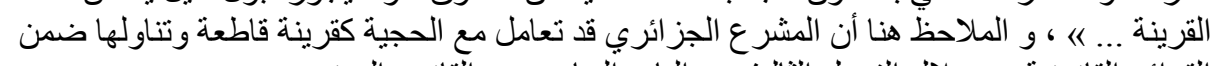

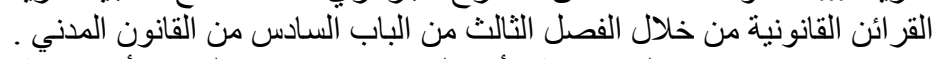

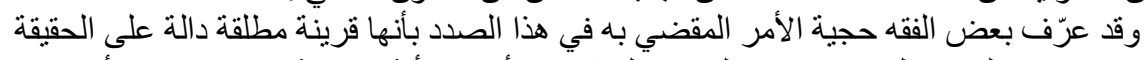

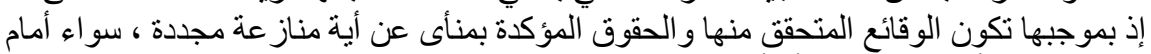

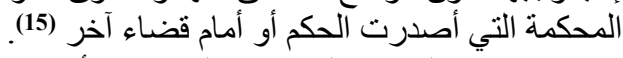

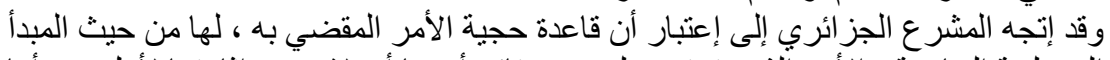

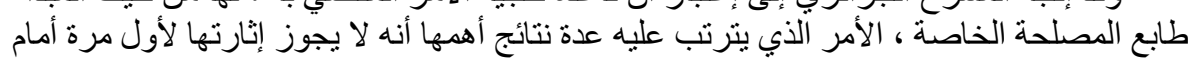


محكمة النقض ، و أنه يجب أن يتمسك بها صر احة من قبل الأطراف و ولا يأخذ بها القاضي من تلقاء

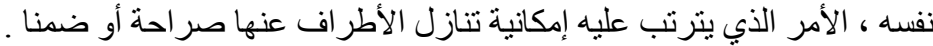

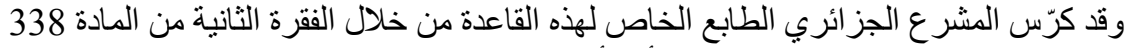

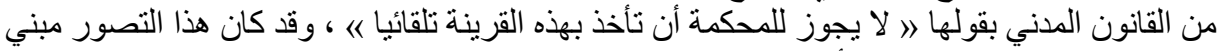

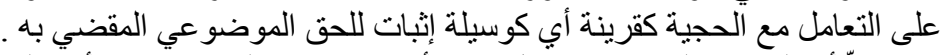

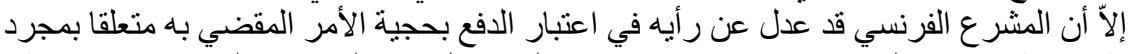

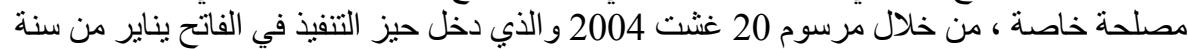

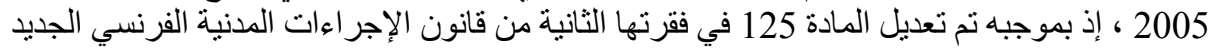

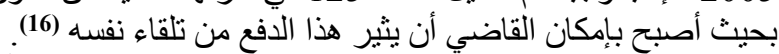

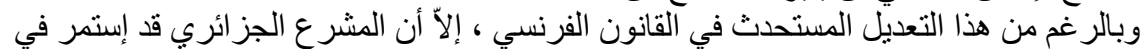

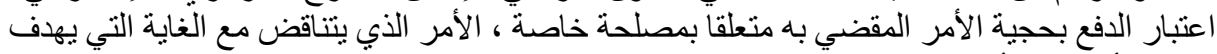

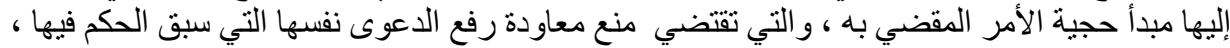

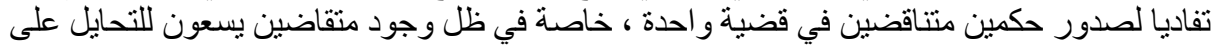

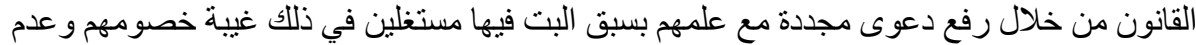

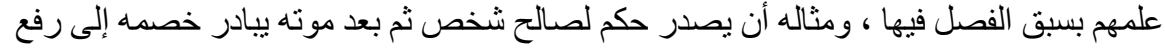

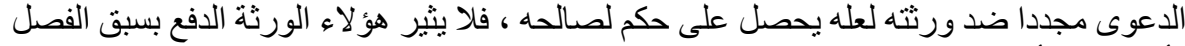

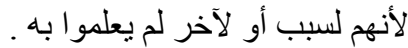

ثانيا : طلب إعادة النظر في الحكم الجنائى النهائى الصادر بالإدانة :

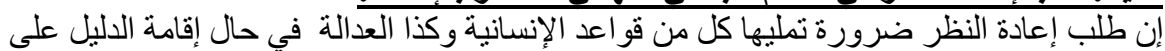

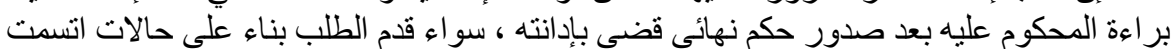

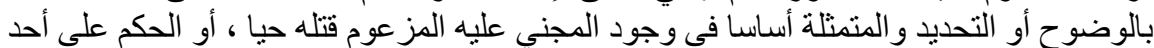

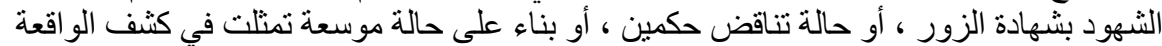

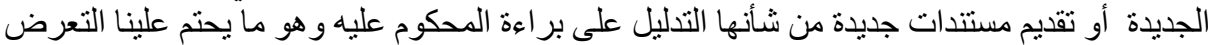

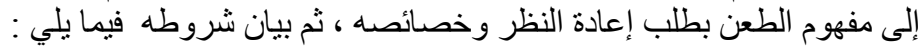

ل)

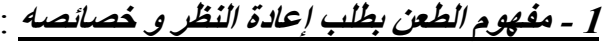

$-1$

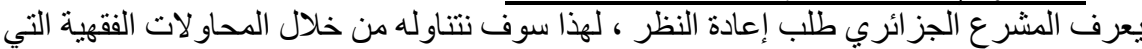

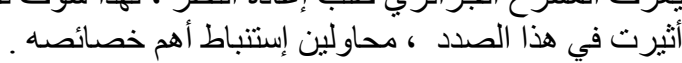

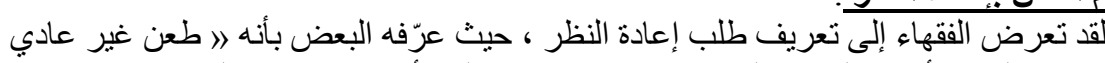

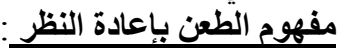

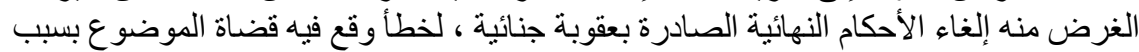

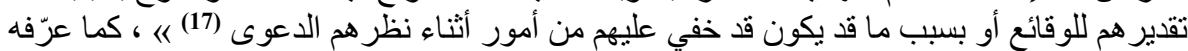

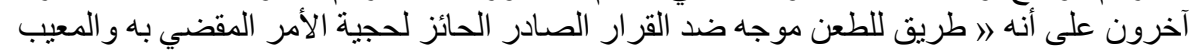

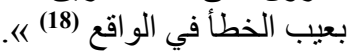

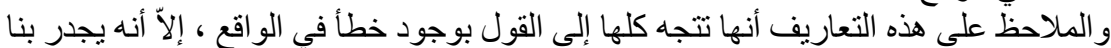

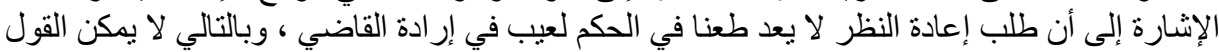

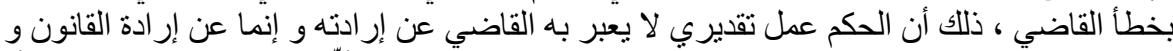

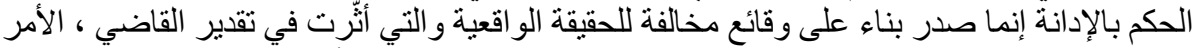

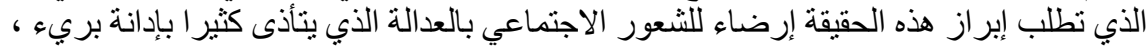

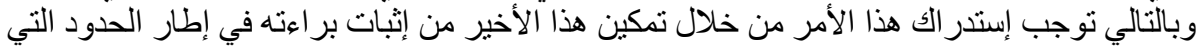
رسمها قانون الإجر اءات الجز ائية . 
ومن

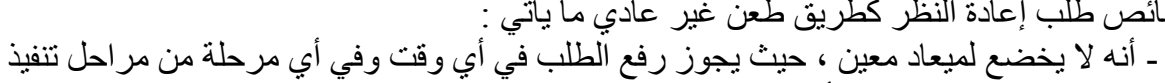

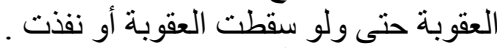

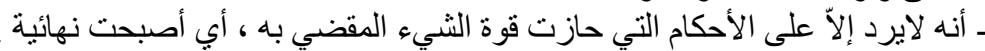

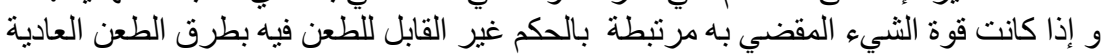

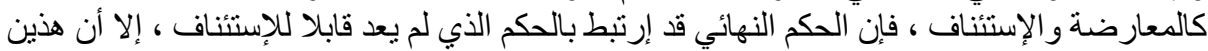

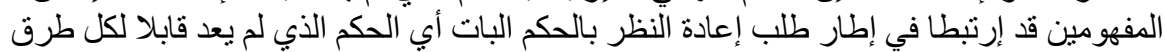

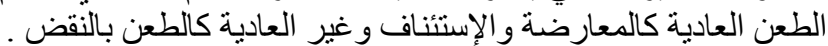

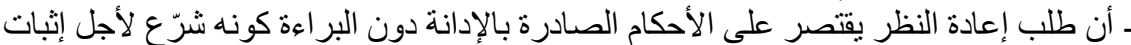

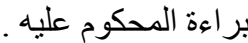
ــ أن الطعن بطلب إعادة النظر لا يجوز إلاّ في الحكم الجنائي الصـادر بالإدانة في الجنايات أو الجنح دون المخالفة ـ أن طلب إعادة النظر ورد طبقا لأسباب وحالات محددة حصر ا طبقا لأحكام المادة 531 من قانون

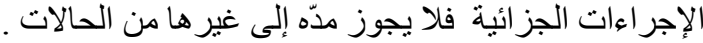

ـ أن الإجراءات المتعلقة بطلب إعادة النظر تختلف عن عن تللك الإجر اءات المتعلقة بطرق الطعن

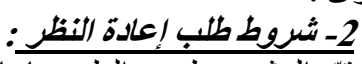

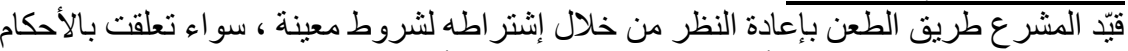

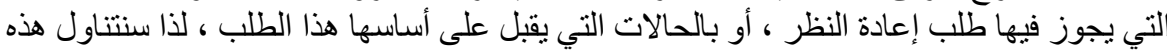

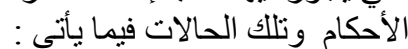

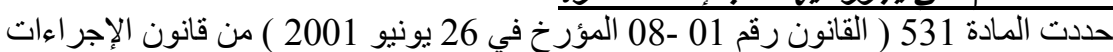

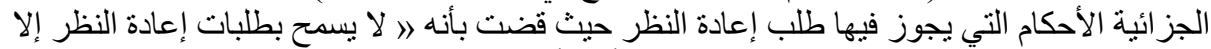

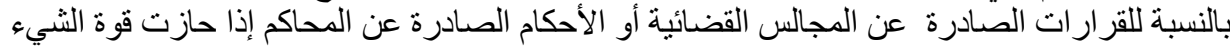

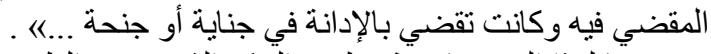

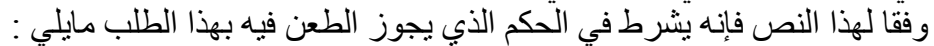

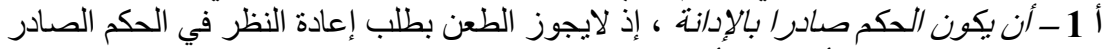

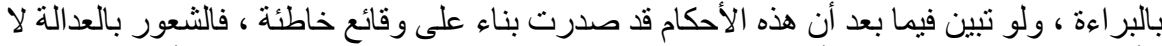

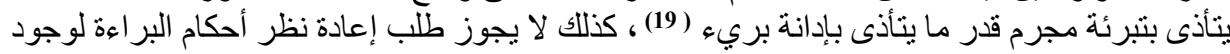

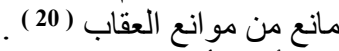

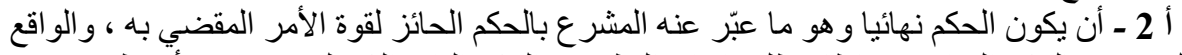

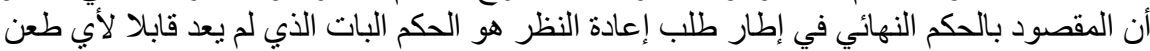

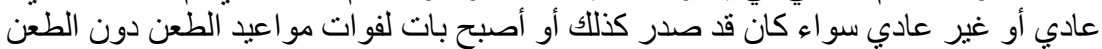

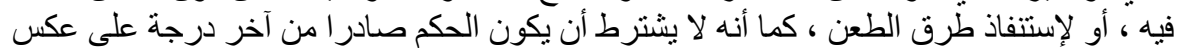

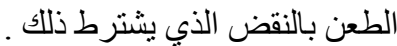

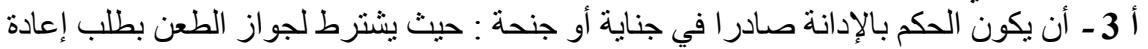

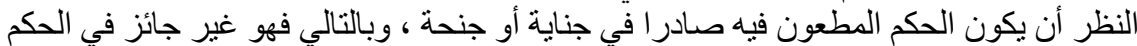

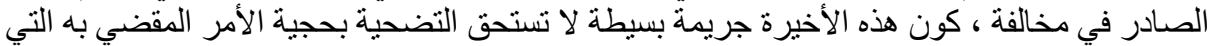

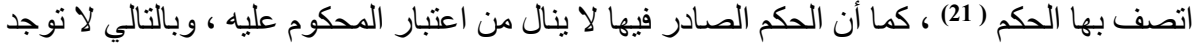
مصلحة جدية للمحكوم عليه في الطعن بطلب إعادة النظر . 
يجوز

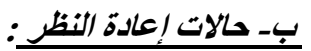

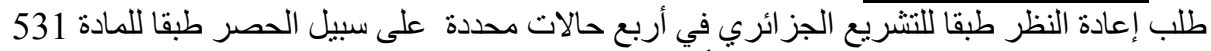

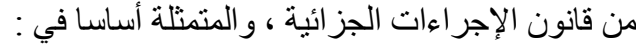

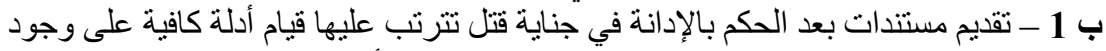

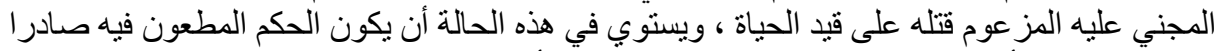

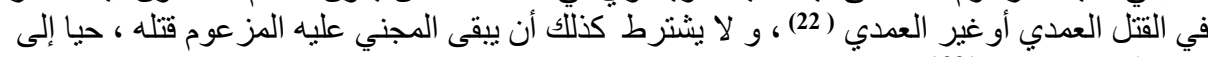

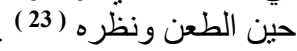

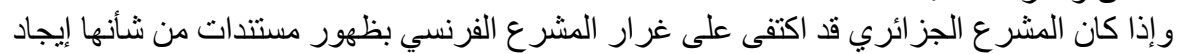

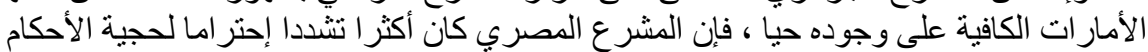

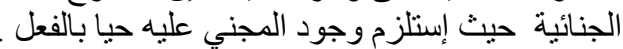

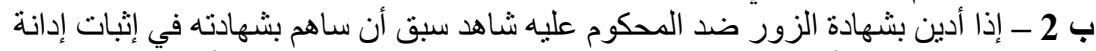

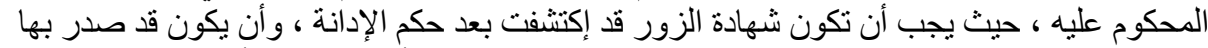

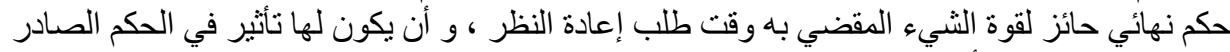

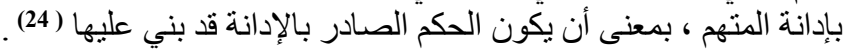

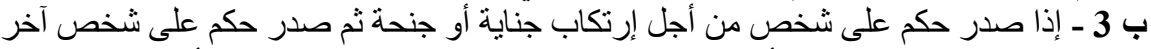

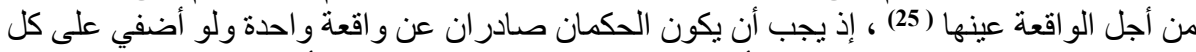

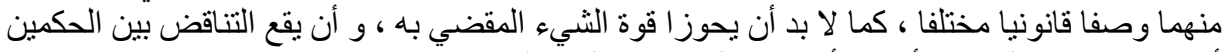

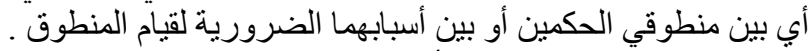

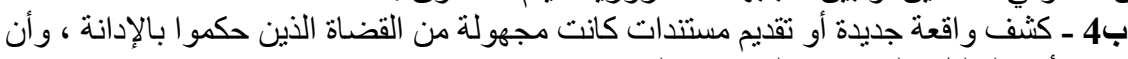

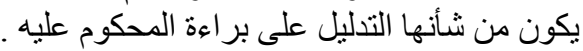

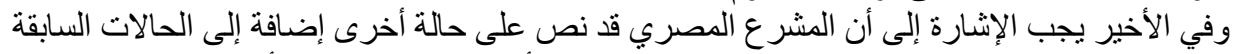

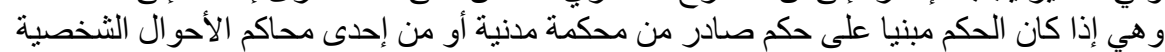
و ألغي هذا الحكم (26) .

3 - مدى تعارض فكرة حجية الأمر المقضي به مع طلب إعادة النظر في الحكم الجنائي

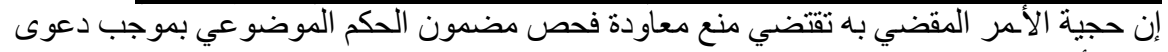

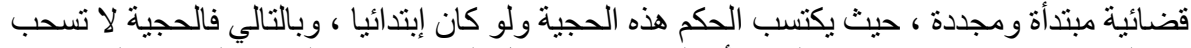

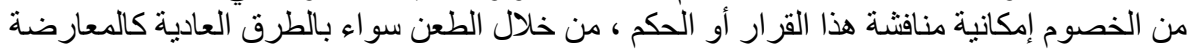

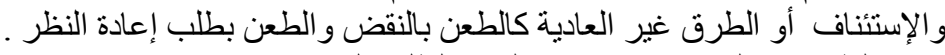

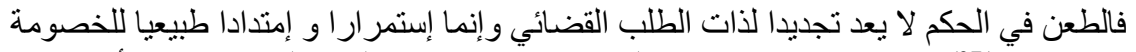

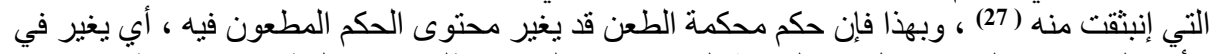

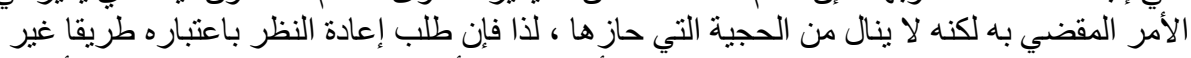

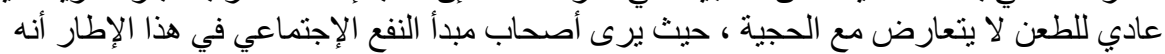

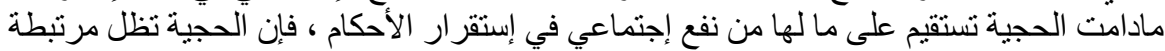

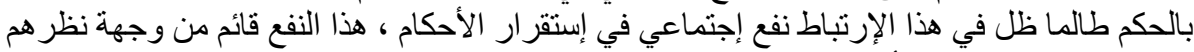

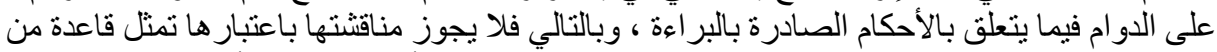

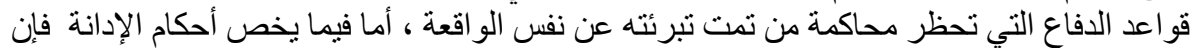

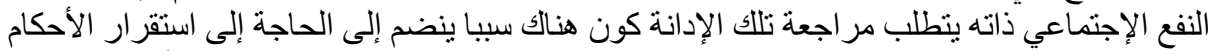

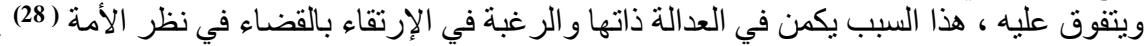

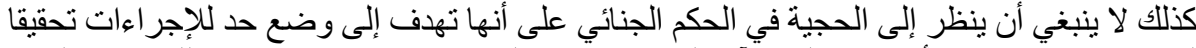

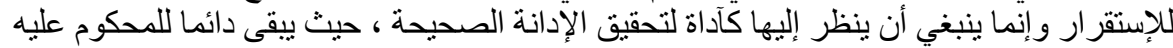

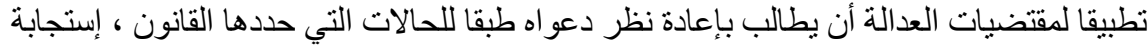

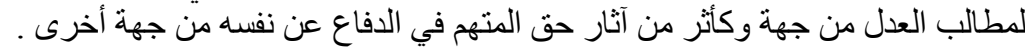


يبدو لنا من خلال ما جاء في هذا المقال أهمية حجية الأمر المقضي به ، إذ تضفي إلى على على الحكم

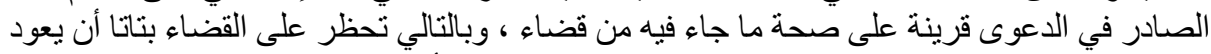

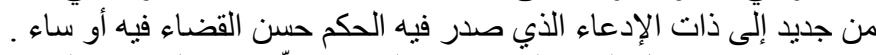

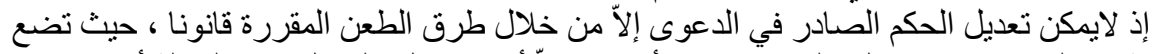

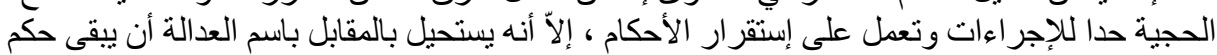

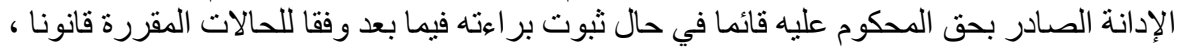

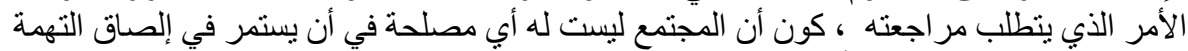

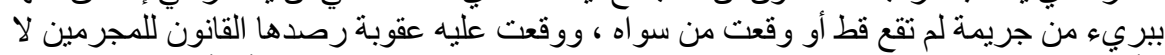

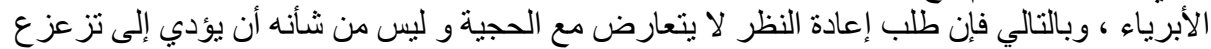

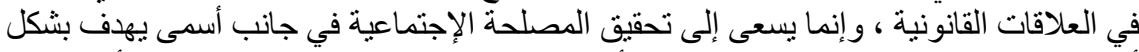

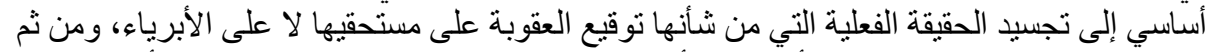
فإن طلب إعادة النظر عامل من شأنه رفع شأن القضاء لا الدس بهييته ، تحقيقا للعدالة في أسمى معانيها

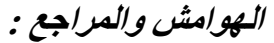

( 1 ) زيد يوسف جبرين : المسؤولية المدنية للدولة عن أعمال السلطة القضائية ، در اسة مقارنة ، دار

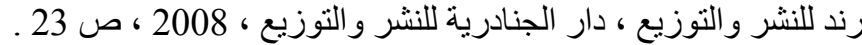

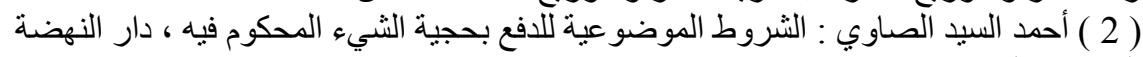

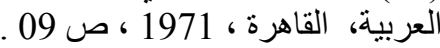

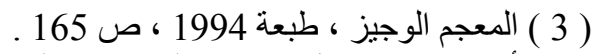
( 4 ) أبو نصر إسماعيل بن حماد الجو هري :الصحاح ، طبعة دار الفكر ، 1998 ، الجزء الثاني ، ص

( 5 ) وحيد محمود إبر اهيم : حجية الحكم الجنائي على الدعوى التأدييية ، در اسة مقارنة ، إدارة تبادل

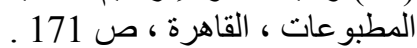

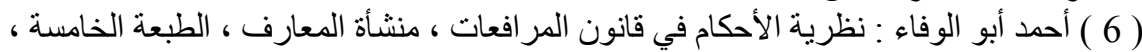

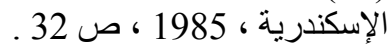

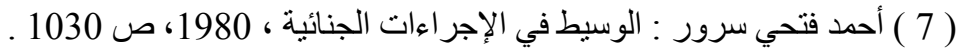

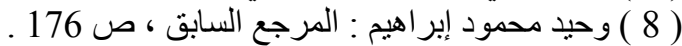

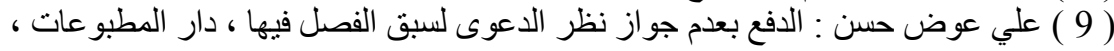

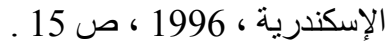


( 10 ) محمد زكي أبو عامر : الإجراءات الجنائية ، دار الجامعية الجديدة للنشر، الإسكندرية ،2005، ص 878.

( 11 ) أحمد فتحي سرور : الوسيط في قانون الإجر اءات الجنائية ، الطبعة السابعة ، 1993 ، ص 181 .

( 12 ) جمال الطاهري : حجية الأمر المقضي في المادة المدنية ، محاولة حد وتحديد ، در اسة تأصيلية

مقارنة مركزة في القانونين المغربي و الفرنسي للآدفع بسبق الفصل ونطاق تطبيقية ، الطبعة الأولى ،

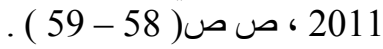

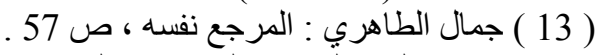

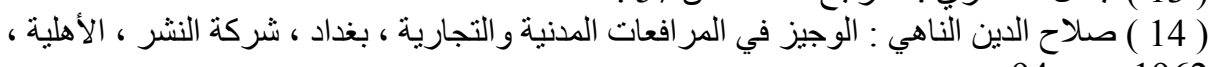

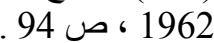

(R ) Morel : Traité élémentaire de procédure civile ,2 éd, paris 1919, ( 15 ) p450,no 577 .

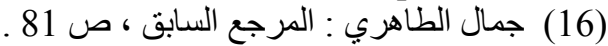

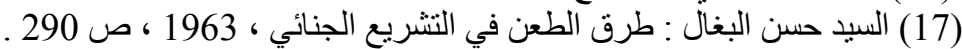

R .Merle , A.vitu : Trité de droit criminel, tome II , ed cujas , 1979 , p (18)

(19) فوزية عبد الستار : قانون الإجر اءات الجنائية وفقا لأحدث التعديلات ، الطبعة الثانية ، دار

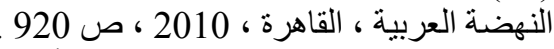
(20) فريجة حسين : مسؤولية الدولة عن أعمال السلطة القضائية ، دراسة مقارنة في في القانون الفرنسي ،

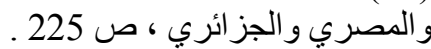
(21) محمود محمود مصطفى : شرئ ، وح قانون الإجر اءات الجنائية ، الطبعة الثانية عشر ، مطبعة جامعة

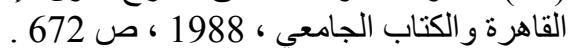

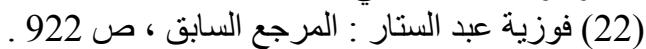

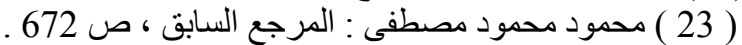

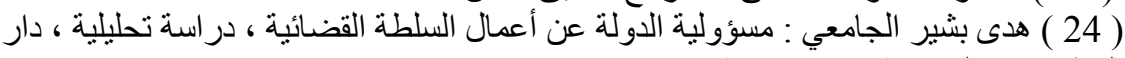

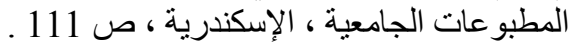
( 25 ) محمد نجيب حسني : شرح قانون الإجراءات الجنائية ، دار النهضة العربية ، 1988 ، 1301 ، ص 1301.

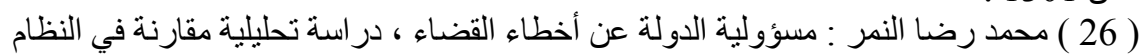
القضائي المصري و الإسلامي ، الطبعة الأولى ، المركز القومي للإصدار الئهات القانونية ، 2010 ، ص 106 صم 106 (28 ) جمال الطاهري : المرجع السابق ، ص 65 . 65 . ( 28 ) محمد زكي أبو عامر : المرجع السابق ، صل صل 511. 